\title{
The Role of Tangible Interfaces in Enhancing Children's Engagement in Learning
}

\author{
Hestiasari Rante $^{1,2^{*}}$, Michael Lund ${ }^{1}$, and Doris Caliz ${ }^{3}$ \\ ${ }^{1}$ Department of Computer Science, University of Bremen, Bibliothekstraße 1, 28359 Bremen, \\ Germany \\ ${ }^{2}$ Department of Creative Multimedia, Electronics Engineering Polytechnic Institute of Surabaya, \\ Jl. Raya ITS-Sukolilo, Surabaya 60111, Indonesia \\ ${ }^{3}$ Department of Pervasive Computing Systems, Karlsruhe Institute of Technology, Vincenz-Prießnitz- \\ Straße 1, 76131 Karlsruhe, Germany
}

\begin{abstract}
This paper presents the results of an exploratory study in which the authors investigated the impact of tangible interface used by children at the elementary school level. Exploration of the viability of graphics tablet and the pen tool was conducted by investigating the children's ease in acclimating to the technology and the effectiveness in engaging them to complete some tasks. Several children were invited to a workshop where they learned and played BatiKids, a game-based learning developed to support children in learning the process of making Indonesian hand-written batik. The qualitative analysis based on the notes and video recording taken on the field observational, and the responses to interview questions to the participants. The results show the main findings and discuss the design implications for a tangible interface in the context of BatiKids.
\end{abstract}

Keywords: BatiKids, children, tangible interface, user interface

\section{Introduction}

Xie et al. [1] mentioned that tangible interfaces and tangible interaction are terms that nowadays progressively increasing within the Human-Computer Interaction community [2]. The last decade has shown a wave of new research concerned with the coupling of the physical and digital worlds [1]. Marshall [3] stated that tangible interfaces are reflecting a greater emphasis on the role of the physical body and environment in embodied interaction $[2,4,5]$. Many different research projects have studied enabling technologies, usability aspects and various applications of tangible user interfaces $[2,6,7]$.

The authors' interest in repurposing a device such as a graphic and pen tablet for media control stems from the authors' dissatisfaction when children using the mouse, either with cable or wireless, in completing the tasks on BatiKids. BatiKids is a game-based learning designed to support children in learning the process of making Indonesian hand-written batik [8-10]. The hand-written batik is a traditional way of producing batik using canting, a tool like a pen that holds a small reservoir of hot wax applied on a fabric [11].

*Corresponding author: rante@uni-bremen.de, hestiasari@pens.ac.id 
BatiKids has two levels. In the Level 1, children have to do some tasks including selecting a batik pattern, drawing the pattern following dots, then coloring the pattern by choosing one color or they can also mix two or three different colors, and the last is multiplying the pattern. Level 2 has the same structure as Level 1 with additional features such as resizing, rotating, and flipping the pattern $[8,9]$. Initially, a mouse was used as the media to control and to complete all the tasks. After some trials, it was noticed that children had difficulty using the mouse particularly when it came to the phase of drawing. In addition, it was also noted that they lost the enjoyment that supposed to be gained when playing BatiKids.

For the above reasons, a decision was made to use a graphics and pen tablet as a media control to replace the mouse. In the next sections, there is a justification that the graphic and pen tablet is not only useful to facilitate children in drawing, but it also enhances children's engagement in learning the process of making batik as if they were using the real canting.

\section{Tangible interfaces for Learning}

Can tangible interface enhance children's engagement in learning?

$\mathrm{Xu}$ [12] argued that historically children have played with physical objects to learn various skills. Therefore, a tangible interface would appear as a 'natural' form to them. She gave an example of the museum project 'Everyday Technology' launched by the University of Limerick museum projects [13], where paper, books, and other physical displays have been augmented digitally. In one spot they provided an antique desk with a projection on the book. As the user turns the page to reveal the marker they will see an image overlaid onto the page of the book. The exhibitions like this create a unique museum visiting environment. It may appear to children as 'magical', interesting, and unforgettable experience [12].

There are a number of reasons why using tangible interfaces may be of particular benefit for learning [3]. Both theoretical and exploratory work on tangible interfaces has suggested that they could be particularly suitable for engaging children in playful learning [e.g. 14]. Furthermore, Marshall [3] described that novel links between physical activity and digital effects might lead to increased engagement and reflection in learning [15]. As interaction with tangible interfaces is assumed to be more natural or familiar than with other types of interface $[4,16]$, they might be more accessible to young children, to people with learning disabilities, and to novices [17], they lowering the threshold of participation [2].

$\mathrm{Xu}$ [12] even explained the benefits in more detailed. Tangible interfaces can benefit children's learning from many ways. The interface requires little time to learn how to use it as if it is a natural interface which requires little cognitive effort to learn. Therefore, children can concentrate more on the task rather than how to use the computer or software. The tangible interface can offer a variety of interactions; it allows user to solve problems with concrete physical objects and physical activity when they fail using more abstract representations and complex syntax. Therefore, the interface can empower children with the control of the computing environment; they will feel and 'own' the environment and will be actively engaged and not lose their interest easily. The tangible interface supports trial-anderror activity as it gives a continuous presentation of the object of interest. It uses rapid incremental and reversible actions whose impact on the object of interest is immediately visible. Another advantage of using a tangible is that it is no longer restricted to a single user, children can sit down and collaborate with their friends face to face in an entirely natural way. It can provide children with a social experience. Also, research shows that children are more productive when they cooperate. Therefore, compared to a single child a 
group of children may be able to do a task more efficiently and benefit more from the experience. Furthermore, the benefits of tangible interfaces in learning have been already well demonstrated by many researchers $[14,18,19]$.

In addition, from psychologist and educationist point of view [20], tangibles are beneficial for learning because the following reasons; i) physical activity is important in learning; ii) concrete objects are important in learning; iii) physical materials give rise to mental images which can then guide and constrain future problem-solving in the absence of the physical materials; iv) learners can abstract symbolic relations from a variety of concrete instances; and v) physical objects that are familiar are more easily understood by children than more symbolic entities [12].

\subsection{Graphic and pen tablet}

Felton [21] defined that a graphics tablet-also called drawing tablet or digitizer-is an input device with the pen tool or stylus used primarily by digital artists, although many nonartists use it as well. These graphics tablets have a hard plastic, touch-sensitive drawing surface that delivers pen stylus, whose function as a mouse, movements to a monitor or screen. The position of the stylus is correlated directly to the cursor position of on the screen. For some people, it takes a while to get used to drawing on the tablet surface, but once the learning curve is overcome, it will be as natural as using a pen or pencil on paper.

After the authors found out that children had difficulty in doing a particular task on BatiKids using a mouse, it was then decided to replace the mouse with a graphic and pen tablet. In particular, Intuos Creative Pen Tablet from Wacom was chosen. The tablet surface is designed super slim and compact, but it is still as durable and powerful as ever. Whilst the pen tool is designed ergonomic and lightweight, make it sit comfortably in hand, allowing user to experience both precision and control (https://www.wacom.com/enus/products/pen-tablets/wacom-intuos\#Features). These features make this selected graphics and pen tablet ideal for children.

\subsection{Pen tablet as canting}

Canting is one of the main tool required to produce batik. Holding canting filled with hot melted wax and moving it carefully to make a pattern on the white fabric is not easy. It is not only about the skill, but also considerable patience and concentration to fully control the flow of the wax in the canting.

Using a graphics tablet and the stylus while learning and playing on BatiKids is a way to translate the physical batik processing and the environments into digital space. The pen tool will teach user's hand movements in relation to the use of canting in the real process. By using the tool, children will get the sense of moving canting on fabric [10]. This function justified the benefit of using a stylus instead of a mouse, in the context of BatiKids.

\section{Workshop}

As the main part of the research, a two-day workshop was conducted in an elementary school, International School of Bremen. Eight international students from the different country and diverse cultural background were involved in the workshop. Their ages range from $10 \mathrm{yr}$ old to $11 \mathrm{yr}$ old. The objective of the workshop was to examine children's ease in acclimating to the technology of graphic and pen tablet and the effectiveness in engaging them to complete several tasks provided on BatiKids. 
A set of pre-test and post-test questionnaires were prepared, also a camera and video camera as well to record the whole activity. When doing the interviews in the workshop, it is very important to watch and listen to children carefully in order to collect relevant data of their difficulties and successes along the test. Recording the children while interacting with the system is also very relevant because recordings can be useful for perceiving events and behaviours not noticed during the test. From the video recordings, it could be identified which of the tasks children had more difficulties with, and how well they successfully completed them. This observation helped the authors to think of alternative designs that better supported the application's workflow [22].

Before started the workshop, the authors carefully set up and planned the environment so that children would feel comfortable when performing the test. A computer and the graphics and pen tablet were placed on the desk that children used every day in the class. The authors also prepared a scenario for running the tests and divided the workshop into four phases: introduction, pre-test questionnaire, usability test, and post-test questionnaire. BatiKids stickers were brought into the workshop, to be given as complimentary for the participants.

In the introduction phase of the workshop, a close relationship with children was established in order to make them feel more comfortable. Introduction of the authors was necessary along with delivering an overview of the application, the tasks, and the learning objectives. As none of the children have ever used graphics and the pen tablet, it was essential to give them a brief information about the function.

BatiKids has four main learning objectives: i) to motivate children to learn the real process of making batik; ii) to understand the philosophy of the batik patterns; iii) to teach how to mix colors, and iv) to teach hand movements in relation to the use of canting in the real process. Due to the limited time, it was not possible to talk deeper to find out more about the children. If more time were available, the authors would have tried to engage children in evoking joyful memories in order to make them feel more comfortable [23].

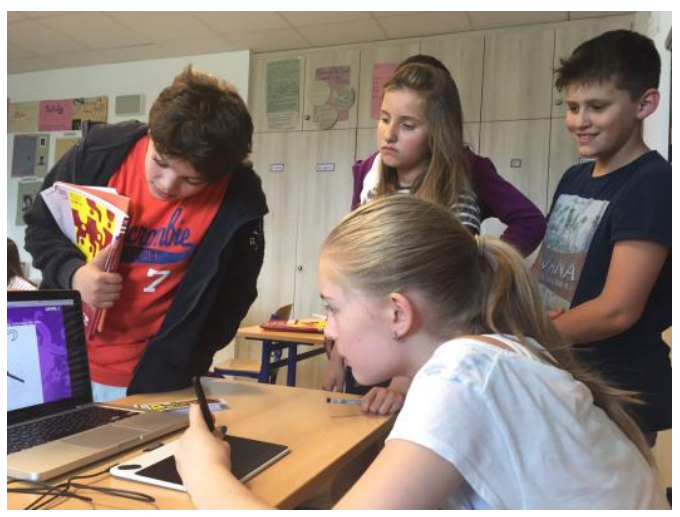

Fig.1. A child using the graphic and pen tablet.

Figure 1 shows a child playing BatiKids using the graphic and pen tablet in the workshop. This set of interface enabled children to see what they draw directly on the screen. The graphics tablet with pen immediately provided handwritten input to the screen of the computer. Observation showed that, somehow, this interaction was not easy due to the separation between the eye reference and hand movements. Children had to move their hand on the tablet while keeping their eyes on the screen. Sometimes, they lose the sight of the cursor on the screen and consequently had to try harder to coordinate their movements with the pen [10]. But the more they moved pen tablet, the more they got used to it. Some interesting comments from the participants were noted. 
"Oh, this is the first time I use this kind of tool ..."

"It's not easy using this pen ..."

"Interesting pen, I like it even it's sometimes not easy to drag it".

"In the beginning, it was hard ... But I'm getting used to it".

The last phase of the workshop was a post-test questionnaire. A list of questions delivered to each participant. In general, children were satisfied with BatiKids; they enjoyed it and got the benefits. They also agreed that the tangible interface used to complete the tasks was helpful. Figure 2 presents an author interviewed a child and helped him to answer the questions.

The issues, indeed, arose mainly came from the application BatiKids itself. Some instructions were unclear for children. Therefore, during the workshop, it is necessary that an author sat next to the children and assisted them when they encountered any issues.

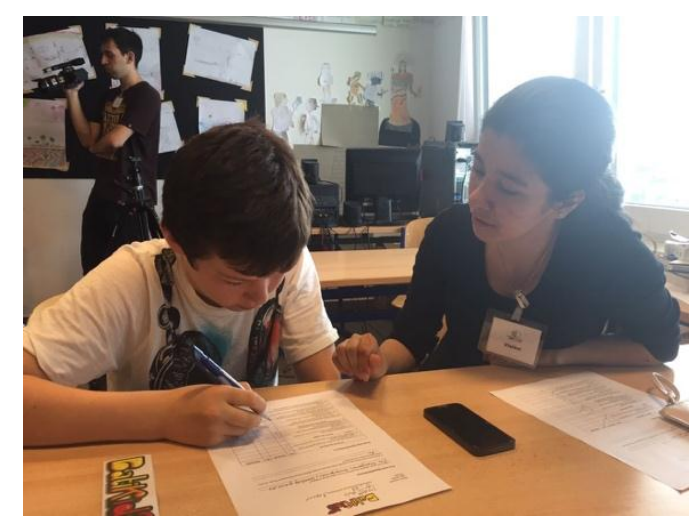

Fig. 2. An interview with a child after the workshop.

Another thing that has to be taken into consideration is there was no information on what user has to do when they made a mistake and needed to recover their work. This matter happened particularly when it came to the task of colouring the pattern. Some children got into trouble and had to start from the beginning because they did not know how to remove the wrong colour and change it to the new one. In fact, they could simply choose the new colour and cover it on the wrong colour; it will automatically alter the colour to the new one. For this reason, it was considered that more information should be added to BatiKids, either as text narrative or voice-over.

"I made mistakes and I did not know how to fix it, so I clicked BACK button, but then I lose all the colours".

"I made two-times mistakes ..."

"Why there is no DELETE button here?"

\section{Results}

The result of eight children interacting with BatiKids through the graphics tablet with the pen is shown in Figure 3. The task of creating or drawing the pattern was the most difficult part for children in this group. Half of the children in this group had to spend more time to complete this task. Hand movements with pen on the tablet required patience and concentration from children.

When the children working with the pen on a graphics tablet, some of them had to struggle when moving the pen of tablet surface. It was clearly seen that many of them had to try several times to get the right point where the pen connected to the point on the screen. 
This issue decreased the concentration and some of the children even lose their patient when facing this matter. This even looked worse to left-handed students. Since the graphics tablet was installed to be used with the right hand, then it became harder for the left-handed to move the pen.

However, by the end of the workshop, all children were conscious and got the point of the importance of canting in making hand-written Indonesian batik. Nevertheless, in order to allow a more tangible experience, the employment of the graphics tablet with the pen is essential, because it drives the children to perform similar hand movements as if they were using canting. Using tangible interfaces can also be more engaging and keep children interested in using the application [12].

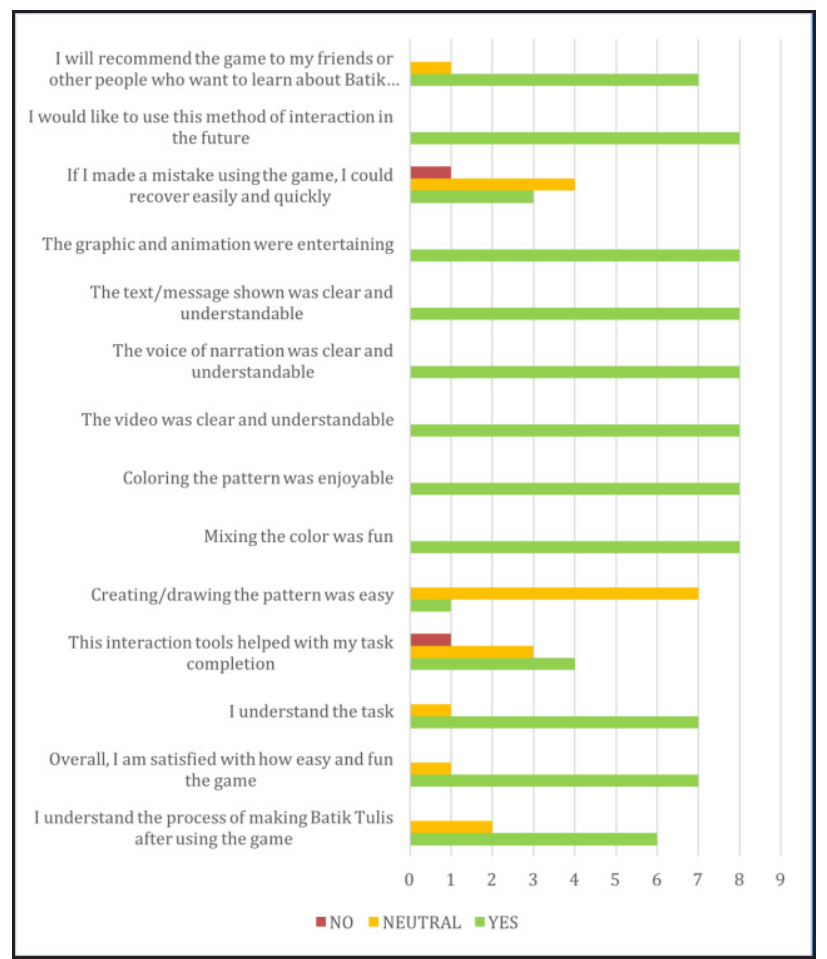

Fig. 3. Results of the interview after the workshop.

At the end of this section, some drawing results designed by the participants at the workshop is attached. Their drawing is shown in Figure 4. 

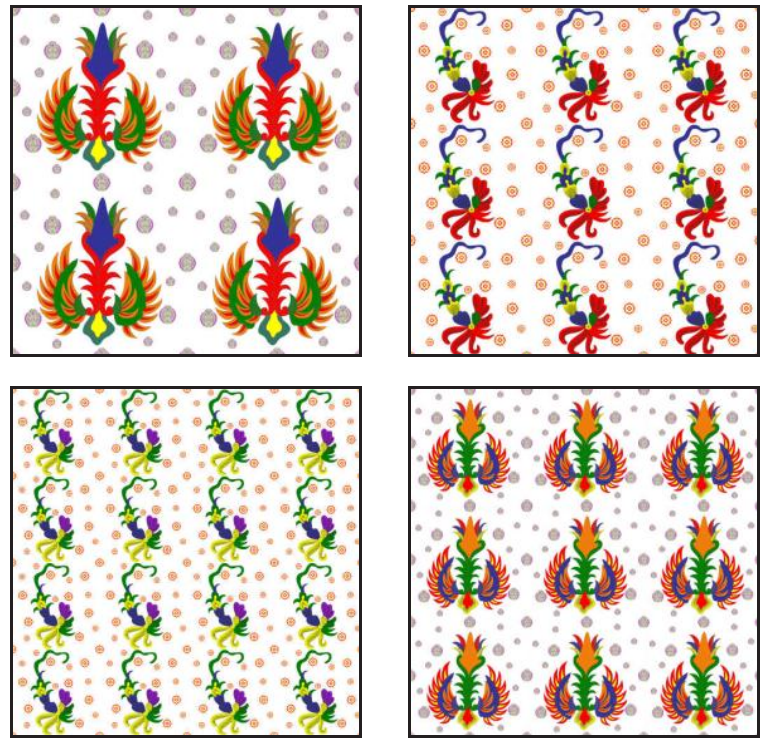

Fig. 4. Drawing results of the workshop.

\section{Summary}

As mentioned in the Results section, one of the problems with the graphics tablet with the pen is the dissociation between the movements performed with the pen and the generated images as a result of this movement. The visuals are displayed on an ordinary monitor far from the pen. The authors believe that better results can be achieved with the use of smart tablets that allow drawings to be created through direct contact of a stylus against a screen. The child, therefore, would be able to see the drawings as a result of the path through which the pen touches the monitor. In this way, the canting process can be represented with a higher degree of likeliness [10].

Likeliness between action and representation is an important factor especially for children in the phase of concrete operations, as they would experience the application with a better understanding of the overall batik process, which is mainly manual. The application would neither be oversimplified by touch user interfaces nor too confusing because of dissociation generated by pen tablets [10].

From the experiments with BatiKids, it is summarized that tangible interface is a natural interface, due to its role that gives user the chance to be more explorative and expressive. The pen tablet used to complete the tasks has successfully given the children the sense of using canting as if they were making batik in the real process. The results of the workshop lead us to further improvement on BatiKids.

In general, $\mathrm{Xu}$ [12] also concluded that the tangible interface supports a better collaborative work compared to others. The tangible interface even has greater potential, if there is enough technology support. In many ways, the tangible interface can be beneficial to children in learning.

Research in a relatively new area raises more questions than it answers, and this work is no exception. For further works in the field of Computer Science, there is a multitude of applications in the general area of Ubiquitous Computing and Tangible User Interface to be discovered [12]. 


\section{References}

1. L. Xie, A.N. Antle, N. Motamedi. Are tangibles more fun? Comparing children's enjoyment and engagement using physical, graphical and tangible user interfaces. Proceedings of the Second International Conference on Tangible and Embedded Interaction (TEI'08) (Bonn, Germany, 2008). Tangible and Embedded Interaction:191198.

http://citeseerx.ist.psu.edu/viewdoc/download?doi=10.1.1.518.5338\&rep=rep1\&type=p df.

2. E. Hornecker, J. Buur. Getting a grip on tangible interaction: A framework on physical space and social interaction. Proceedings of CHI 2006 (Montreal, Canada, 2006). Proceedings of CHI 2006:437-446. (2006). http://citeseerx.ist.psu.edu/viewdoc/download?doi=10.1.1.122.9553\&rep=rep1\&type $=$ p df.

3. P. Marshall. Do tangible interfaces enhance learning? Proceedings of the First International Conference on Tangible and Embedded Interaction TEI'07 (Baton Rouge, USA, 2007). Tangible and Embedded Interaction:163-170.

https://dl.acm.org/citation.cfm?id=1227004

4. P. Dourish. Where the action is: The foundations of embodied interaction. USA: MIT Press, 50-53 (2001). https://mitpress.mit.edu/books/where-action

5. S.R. Klemmer, B. Hartmann, L. Takayama. How bodies matter: Five themes for interaction design. Proceedings of the Sixth Conference on Designing Interactive Systems (DIS '06) (University Park, USA, 2006). Proceedings of the Sixth Conference on Designing Interactive Systems (DIS'06):140-149. (2006). https://dl.acm.org/citation.cfm?id=1142429

6. L. Holmquist, A. Schmidt, and B. Ullmer. Personal and Ubiquitous Computing, 8, 5:291-293 (2004). https://dl.acm.org/citation.cfm?id=1023814

7. Y. Rogers and H. Muller. Journal of Human Computer Studies, 64, 1:1-14 (2006) https://www.sciencedirect.com/science/article/pii/S1071581905001126

8. H. Rante, H. Schelhowe, M. Lund. International Journal of Information and Education Technology, 6, 7:580-583 (2016). http://www.ijiet.org/vol6/755-T061.pdf.

9. H. Rante, H. Schelhowe, M. Lund. Paper prototyping for BatiKids: A technique to examine children's interaction and feedback in designing a game-based learning. Proceedings of Second International Conference on Electrical Systems, Technology and Information 2015 (ICESTI 2015). F. Pasila, Y. Tanoto, R. Lim, M. Santoso, N. Pah (Eds). Singapore: Springer (2016). pp. 447-455.

https://link.springer.com/chapter/10.1007/978-981-287-988-2 49

10. H. Rante, L. de Araújo, H. Schelhowe. International Journal of Educational and Pedagogical Sciences, 10, 10:3500-3504 (2016). https://waset.org/publications/10005779/usability-testing-with-children-batikids-casestudy.

11. H. Rante, M. Lund, and H. Schelhowe. International Journal of Multidisciplinary Education and Research-IJMER, 1, 2:50-54 (2014).

https://www.researchgate.net/publication/283349024_A_Digital_Batik_Tool_Supportin g_children_in understanding_and_constructing_traditional batik_patterns within_a a $\mathrm{m}$ useum_context

12. D. Xu. Tangible user interface for children - An overview [Online] from http://www.chici.org/references/tangible_user_interface.pdf. (2005). [Accessed on 15 March 2018]

13. K. Ferris, L. Bannon, L. Ciolfi, P. Gallagher, T. Hall, M. Lenno. Shaping experiences in the Hunt Museum: A design case study. Proceedings of the Fifth Conference on 
Designing Interactive Systems (DIS'04) (Cambridge, USA, 2004). Proceedings of the Fifth Conference on Designing Interactive Systems (DIS'04):205-214 (2004). https://dl.acm.org/citation.cfm?id=1013115.1013144\&coll=DL\&dl=ACM

14. S. Price, Y. Rogers, M. Scaife, D. Stanton, H. Neale. Interacting with Computers, 15, 2:169-185 (2003). https://www.sciencedirect.com/science/article/pii/S0953543803000067

15. Y. Rogers, M. Scaife, S. Gabrielli, H. Smith, E. Harris. Presence: Teleoperators \& Virtual Environments, 11, 6:677-686 (2002).

http://ieeexplore.ieee.org/document/6791104/

16. R.J.K. Jacob, H. Ishii, G. Pangaro, J. Patten. A tangible interface for organizing information using a grid. Proceedings of the SIGCHI Conference on Human Factors in Computing Systems (CHI'02) (Minneapolis, USA, 2002). Proceedings of the SIGCHI Conference on Human Factors in Computing Systems (CHI'02):339-346 (2002). https://dl.acm.org/citation.cfm?id=503437

17. O. Zuckerman, S. Arida, M. Resnick. Extending tangible interfaces for education: Digital Montessori inspired manipulatives. Proceedings of the SIGCHI Conference on Human Factors in Computing Systems (CHI'05) (Portland, USA, 2005). Proceedings of the SIGCHI Conference on Human Factors in Computing Systems (CHI'05):859-868. (2005). https://dl.acm.org/citation.cfm?id=1055093

18. N. Ditter. TechSportiv: Constructing objects-to-think-with for physical education. Proceedings of the 8th Nordic Conference on Human-Computer Interaction: Fun, Fast, Foundational (NordiCHI '14) (Helsinki, Finland, 2014). Proceedings of the 8th Nordic Conference on Human-Computer Interaction: Fun, Fast, Foundational (NordiCHI '14): 569-577 (2014). https://dl.acm.org/citation.cfm?id=2639202\&dl=ACM\&coll=DL

19. K. Lee, D. Jeong, R.C. Schindler, E.J. Short. Computers in Human Behaviour, 65:163175 (2016). https://www.sciencedirect.com/science/article/pii/S0747563216305878

20. C. O'Malley, D.S. Fraser. Literature review in learning with tangible technologies [Online] from https://www.nfer.ac.uk/publications/FUTL69 (2004). [Accessed on 15 March 2018]

21. J. Felton. Do you need a graphics tablet? Find out what you need to know [Online] from https://design.tutsplus.com/articles/do-you-need-a-graphics-tablet-find-out-what-youneed-to-know--vector-13586 (2013). [Accessed on 16 March 2018]

22. J. Rubin, D. Chisnell. Handbook of usability testing: How to plan, design and conduct effective tests. 2nd edition. USA: Wiley Publishing, Inc. (2008). pp. 54-57

https://www.amazon.com/Handbook-Usability-Testing-ConductEffective/dp/0470185481

23. L. Hanna, K. Risden, and K. Alexander. Guidelines for usability testing with children: Methods \& Tools [Online] from https://www.microsoft.com/usability/UEPostings/p9hanna.pdf. (1997). [Accessed on 16 March 2018] 